\title{
MEDICAL INSPECTION OF SCHOOLS AND SCHOOL CHILDREN.
}

\author{
By J. B. Story, Esq, M B. \\ [Read, December I 5th, I9I I ]
}

IN February last I read a short paper on this subject before the State Medicine Section of the Royal Academy of Medicine in Ireland, in which I drew the attention of the Medical Profession to the absence of any such medical inspection of schools and school children in Ireland, and pointed out some of the benefits that had been conferred upon the children of Great Britain by the recent Education Acts.

That paper was published in the Dublun Journal of Medical Sczence and is now embalmed in the Transactions of the Academy for the benefit of future archæologists, and the only good it may have effected is that possibly it may have influenced my friend, Mr. Gogarty, to deal with this question in his admirable address at the opening of the Medical Session in the Meath Hospital.

I am very pleased to have the opportunity of bringing this subject before an important Society like ours, which is restricted to no class or profession, in the faint hope that some of those competent to deal with it (as I am not) may take it up, not as an interesting theory, but as a practical reform, and succeed in introducing medical inspection as a regular proceeding in our Irish Primary schools.

That this reform will come sooner or later is absolutely certain. It has been included in the programme of that admirable Society, the Women's National Health Association, which Ireland owes to the wisdom and public spirit of Her Excellency the Countess of Aberdeen. Under the section of school hygiene amongst the objects of this Association, the promotion of the medical inspection of schools and school children in elementary schools and the visiting of such schools by trained nurses is advocated, and the desire expressed that the medical inspection of schools begun in Great Britain in I907 should be extended to Ireland.

Medical inspection of school children exists in a more or less complete form in every civilised community except our own, as can be learned in a book entitled: "Medical Examination of Schools and Scholars," edited by Dr. Kelynack, and published last year. 
It contains a ser1es of monographs on medical examination of schools in England, Wales, Scotland, Canada, Australia, New Zealand, the United States, Germany, France, Norway, Sweden, Denmark, Switzerland, and last and least, Ireland

Professor Lindsay, of Belfast, is the author of the chapter upon Medical Examination of Schools and Scholars in Ireland, and does not content himself with merely copying the distinguished author of the celebrated chapter upon "Snakes in Iceland," as he might fairly have done, but points out the gross sanitary defects already exposed by the reports of lay inspectors, and urges the following essential reforms:-

I. The primary schools should be put under popular local control, and a sweeping reform regarding premises and hygienic conditions should be effected.

2. All schools and scholars should be subject to periodical medical inspection.

3. A health schedule should be kept of every pupil, in which should be noted the height and weight, and condition of sight and hearing, the state of the teeth, the condition of the heart, and other important organs, the games in which the pupil may, or may not indulge, and any constitutional peculiarity.

4. Systematic teaching of hygiene should be enforced, and steps should be taken to institute courses of lectures and other methods for instructing school teachers in this subject

5. Ambulance or first-aid classes should form a necessary part of school routine.

The subject divides itself naturally into four heads:-

I. What does medical inspection of schools and scholars mean?

2. What good can it do Ireland?

3. What will it probably cost?

4. Where is the money to come from?

The first three of these four questions can be best answered by appealing to English experience.

1. Medical inspection of school children has been in operation in England since January, Igo8.

The Education (Administration Provisions) Act of I 907 added to the duties of a local Education Authority, the duty to provide for the medical inspection of school children on their admission to a public elementary school, and on all such occasions as the Board of Education direct, and added also the power to provide play centres, and to make sich arrangements for attending to the health and physical condition of the children as may be sanctioned by the Board of Education. 
From a Memorandum of the Board of Education (Circular 576), we learn that the duty of the actual inspection 1s thrown on the local Education Authorities, under the advice of the Board. The work has to be carried out in intimate conjunction with the Public Health Authorities, and the Local Education Authorities must appoint medical officers as required.

Regulations of the Board of Education :-

Three inspections will be necessary.

Ist at about time of admission,

2nd at about the third year of school life-this is not yet obligatory-and

3 rd at about the sixth year of school life, or at time of leaving school.

The inspection is to be made on the school premises, and the facts ascertanned must be entered in a register kept at the schools.

The School Medical Officer should make an annual report, etc.

The inspection is to be conducted as in the schedule. (See Appendix). land.

Briefly, this is what medical inspection means in Eng-

We can ascertain some of the good done by medical inspection from the first three annual reports issued by Sir George Newman, the Chief Medical Officer of the Board of Education.

First of all, the schemes of medical inspection have been approved, and the School Medical Officer recognized by the Board in 305 of the 322 local education areas in the educational (code) year, igio-IgI I.

I76 Local Education Authorities have appointed school nurses, or health visitors.

The object of medical inspection is not to compile a mass of statistics, but to ascertain what defects or diseases actually exist in the children in the first place, to investigate their causes in the second place, and then to point out appropriate measures of prevention or cure.

The crucial question 1s, as Sir George Newman writes:- "What is the value of medical inspection to this child ?"

In the first code year, it was calculated that the authorities would have to provide for the examination of I $\frac{1}{2}$ millions of children; and it is estimated that when the Act is in full working order, not less than one-third of all the children attending public elementary schools will be inspected each year; I assume that this means one-third of the number in average daily attendance. 
The results obtained by medical inspection in the first year of its operation were necessarly of a tentative and fragmentary character. For instance, as regards

\section{NUTRITION}

It is stated in the furst Report (page 42) that it is not possible, under this heading, to give figures indicative of the condition of nutrition as found among school children throughout the country, but, in the third report, we find that defective nutrition stands in the forefront as the most important of all physical defects from which school children suffer.

Report 2 omits the question of nutrition entirely.

Report 3 (page 27).

Report 3 gives a table from which it will be seen that the percentage of malnutrition in eleven county areas amounted to $12^{\circ} 9$ per cent. (or 13,561 children out of I04,457 examined).

And out of nine urban areas, the percentage was 123 per cent., or 7,398 children out of 59,908 examined

An interesting report on defective nutrition, by $D_{r}$. Chate-one of the District Medical Officers in Middlesex -1s included in the School Medical Officer's Annual Report Five hundred and seventy children (307 boys and 263 girls), suffering from a condition of nutrition below normal, were made the subject of special enquiry. The chief causes found at work were the following:I.-Poverty, resulting from.-

(a) Father out of work.

(b.) No father; mother goes out to work.

(c.) Father incapacitated; mother works.

(d.) Both parents work.

(e.) Large family with small wages.

The percentage of cases of malnutrition, in which poverty was found to be principal cause was, for boys, 29.5, and for girls, 26.I.

(Report 3, page 29)

\section{2.--Intestinal parasites.}

The percentage of cases of malnutrution due to worms was found to be, for boys, 14.3, and for girls, 15.9.

In this connection, Dr Chate states:- "The origin of worms in the human body is supposed to be through eating uncooked vegetables, watercress, etc. My observation 
leads me to conclude that dirt plays a large part in infectrons, and I am of opinion that if the children's fingers, and especially finger nails, were kept cleaner, the incidence of worms in school children would be much reduced."

\section{3 -Adenoids.}

This seemed to be the main cause in 5.5 per cent. of the boys, and 57 per cent. of the girls, although other conditions were also present.

4 -Rickets.

48 per cent. of the cases of malnutrition in boys, and 30 per cent. in girls, were apparently due to this cause.

5.-Carious teeth and oral sepsis.

In 8.1 per cent of the boys and 87 of the girls this cause was the main one

6.--Improper diet

This cause was the principal one, all others being eliminated, in 23 per cent of the cases cases.

Other causes were found in a small percentage of the

Lastly, the report for London contains some interesting observations on the subject Dr. Kerr writes.The estimate has been recorded in numbers from I to 5 following the scheme used by Dr C J. Thomas, the limits of the groups being defined as -

I The pink of condition.

2 Very good muscular development, with only fair general nutrition as indicated by subcutaneous fat, etc, or vice versa.

3 Fair all-round development.

4. Very poor muscular development, with a faur amount of subcutaneous fat, or moderate muscularity, and little or no fat

5 Very poor muscular development with little or no subcutaneous fat.

At a later stage the classification was reduced to a three-fold table of good, moderate, and bad, good comprising $I$ and 2 of the foregoing, and bad 4 and 5 This reduced the number of border zones in which there was room for personal equation, the observer tending to set a standard by the children in the group actually under observation rather than from the whole in all types of schools This equation affected results when a good type 
school was substituted for a poorer one, and vice versa. The percentage distribution of nutrition has been :-

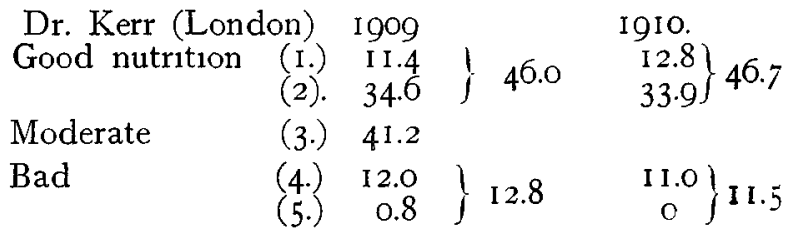

It will be seen, therefore, that not less than I I per cent. of the London children examined were found to be suffering from a greater or less degree of malnutrition.

\section{CLEANLINESS.}

(Report I, page 44).

In the first Report the subject is considered from the point of view of the condition of (I) the body generally, and (2) the head and hair.

To take the latter.

(Report I, page 47).

In a general way, it appears that of the children examined, approximately one-half of the girls in urban areas, and one-quarter of those in rural areas had unclean heads.

In the second Report it is stated that an appreciable Improvement had been brought about (page 29).

That much, however, remained to be done may be gathered from the fact that, on an average only 60 per cent. of the girls in county areas, and 50 per cent. in the boroughs had heads that could be considered clean.

The third Report (page 33) states that the condition of uncleanliness, as evidenced by the presence of head vermin is indicated generally by saying that in ten rural counties taken at random, 70 per cent. of the girls' heads were clean, that $1 \mathrm{~s}$, there were no vermin or nits, whereas in ten typically urban communities, $5 \mathrm{I}$ per cent. only of the girls' heads were found to be clean. It should be remembered that the children from whom these figures are drawn were all examined on the occasion of the routine examination, and that, generally, notices had been sent to the parents.

In the county of Nottingham, Dr. Handford reports that, after examination by nurses of 55,299 girls, 60.8 per cent. were found to have unclean heads

In this connection, I should mention that shower baths have been installed in many elementary schools, and the 
bath avowedly forms part of the training of the child, and is supervised by the teaching staff.

As regards ringworm, the percentage of children suffering from this varied in different areas from i in $\sigma_{3}$ to I in 287 in the second Report. In the third Report we find that in one locality-Shrewsbury-at least 4 per cent. of the children had ringworm during the year, but it is not possible to state the percentage for the whole country. I would suggest, parenthetically, that if hats and caps were abolished it would tend to diminish the spread of this disease.

As regards defective vision, it is stated in the first Report (page 60) that, of the children examined who were about to leave school-approximately io per cent.rather more in the case of girls, and rather less in the case of boys-were in need of careful examination by an ophthalmic surgeon, their vision being what is technically expressed as $6 / 18$ ths, or less than that fraction.

In the second Report (page 5I), one of the most complete and interestıng returns is that furnished by Staffordshire in regard to the eyesight of boys and girls at the ages of 8-9, I2-13, and 13-14, respectively.

The children examined numbered 12,178; the total number found to have defective sight was $3,5 \mathrm{I} 6$, but, of these, 55 were excluded on account of some doubt as to the tests. This reduces the number of the defectives who were further analysed to $3,46 \mathrm{I}$. All cases in which the right eye was normal, while the left had some defect of sight, were selected, and similarly the cases in which the left eye was normal The results may be stated thus:Right eye normal and left defective ... Left eye normal and right defective ... ... Both eyes defective

673 cases or 19.4 per cent.

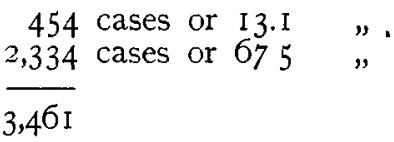

In the Official Report, Dr. Priestly asks the pertınent question: "What degree of eye defect should be considered bad enough to call for treatment either by spectacles or otherwise?"

"There is no doubt that many people suffer very little inconvenience from a defect of $6 /$ I 2 ths. On the other hand, $6 / 18$ ths is a really high and disabling degree of defect. The practical limit for the common purposes of life in civilised countries hes somewhere between these degrees; defects of $6 / 18$ ths always merit treatment, but defects of $6 /$ I 2 ths, if they do not cause headache or other complaint, may often be passed over. 
"If we are right in taking 6/18ths as the point at which spectacles or other suitable treatment should be considered imperative, it follows that 20 per cent. of our recorded cases of defective sight reached this high degree in both eyes, and 37 per cent. in one or both These children, beyond all cavil, will be severely handicapped in life if they cannot have their defects remedied.

"This figure (37 per cent of the eyc-defectives) corresponds to 10.5 per cent. of all the children examined; 10.5 per cent. of all children had the defect 6/I8ths or worse in both eyes"

(Report 2, page 55)-Dr. Wheatley (School Medical Officer, Shropshire), cites six main factors tending to give defective vision, viz.:-

I. Insufficient or improper lighting of the schoolroom.

2 The construction of the desks

3. The type and paper of the books used.

4. The attitude of the children when occupied in near distance work

5. The length of time during which the children are kept at near distance work, and

6. The age at which such work is commenced.

The Third Report (page 37) contains a number of valuable tables and statistics as regards defective eyesight, which are too technical to quote here.

There is, however, an even more important matter connected with the eyes of school children, and that is the detection of contagious ophthalmia in its various forms, and the prevention of the spread of the disease

Every day of my life that I see out-patients in the Eye Dispensary, I see one or more children with some contagious form of eye disease, and there is no officially arranged method of excluding them from school. Indeed, except for my certificate, which I am under no obligation whatever to give, the parents would be prosecuted if the children did not attend school.

Every oculist in Dublin who has studied the question must have seen persons whose sight has heen permanently injured by disease contracted from their school fellowsit may be in national, it may be in industrial, or it may be in charitable schools. None of these persons would be permitted to enter the United States of America. The public are not generally aware that our Islands are used as a filter to exclude persons with diseased eyes from the United States, and these unfortunates, drawii from every 
country in Europe, are collected in Ireland to be treated at our Hospitals, and to contaminate our healthy inhabitants.

\section{DEAFNESS.}

It is difficult to compare the frequency of deafness in different areas, and it is not at present possible to establish standards.

The percentage varied from 6.44 per cent. to over 10 per cent. in the reports of different medical officers.

As regards the causation of deafness, one of the Med1cal Officers in Surrey reports that middle-ear disease with discharge has a percentage of I4; middle-ear disease without discharge, generally associated with enlarged tonsils and adenoids, 65.7 per cent., and ceruminous obstruction, 20.1 per cent (Report 3, page 48).

\section{ADENOIDS, ENLARGED TONSILS, AND GLANDS.}

In the first Report (page 57), various returns are given from the different parts of the country as to the number of children affected, and from 8 to Io per cent. of all children examined on admission into school appears to be the average number suffering from enlarged tonsils and adenoids.

The second Report (page 42) gives the figures obtained by Dr. Stewart in 8,573 children (boys and girls in East Suffolk). Of these, I,422 (I6.6 per cent.) urgently required surgical removal of tonsils and adenoids. The number not urgently requiring surgical treatment, but who could be benefited by operation, was 2,385 (or 27.7 per cent.)

The third Report (page 50) gives the number of children examined as 77,546 in counties, of whom 4,834 were affected-6.2 per cent.; and 51,100 in cities, of whom 2,924 were affected- 5.7 per cent.

\section{CONDITION OF TEETH.}

\section{(Report I, page 53).}

Judging from the Returns, it is generally found that from 20 to 40 per cent. of all school children examined, excluding children in the babies' class, have four or more decayed teeth-the older the child the more extensive the decay-generally speakıng.

A full and detalled report in reference to the teeth of the children is presented by the Cambridge Borough Authorities, the examination having been undertaken by a dentist 
In summing up the condition of the teeth of the 2,946 children examined, the writer states:-

"The percentage of children "with perfectly sound teeth, which, in the third and fourth years, stood at a little over I I per cent., has fallen by the sixth and seventh years to two, and by the tenth to the fourteenth years, to zero.

"Similarly, if the temporary teeth be ignored, the percentage of children with perfectly sound teeth at five years is just over 64 per cent., dropping at seven years to 24 per cent. It then falls more slowly to a little over six in the ninth year, and, after contınuing almost stationary until the tenth year, sinks to less than two in the eleventh, and after this remains more or less stationary."

Further, speaking later of the permanent teeth only, the report states that "at I 3 and I 4 years half the children have each nine or more permanent teeth carious."

(Report 2, pages I25-6-7.)

One of the most complete dental reports is that recelved from Mr. A. W Gant, Borough Dentist at Cam. bridge. During 1909, the number of children specially examined for dental defect was 2,843, of whom I,288 were treated. Among the children whose teeth were examined for the first time $(1,632)$ only 2.6 per cent. were found having teeth entirely free from caries (as compared with 2.4 per cent. among 3,000 children in I908). Even at the age of three and four years, more than 30 per cent of the temporary teeth were carious. At six years of age the average number of sound and carrous teeth was found to be approximately equal, and every year after shows an increasing proportion of carious to sound teeth.

Upwards of 70 per cent. of children between $7 \frac{1}{2}$ and $8 \frac{1}{2}$ years of age need dentàl treatment.

The average number of carious permanent teeth per child at the age of 13 years 1 s between 9 and I $I$, two of which are unsaveable.

The third Report (page I67) includes a Table, illustrative of the condition of things existing, from which it is seen that, whilst the returns differ so widely as to suggest considerable differences of standard, there 15 general agreement (a) that the largest amount of soundness is to be found in the entrants; (b) that the largest amount of decay exists among the elder school children, and $(c)$ that if the children with somewhat defective teeth and with grossly defective teeth be added together, the total percentage gives a proportion of from 52 to 99 as defective and requiring treatment. 
The Germans appear to have taken the lead in the treatment of dental defects of school children. In Berlin alone over 25,000 children are annually treated by the State dentists at a cost varying from is. Id. to gd. per child treated.

In England, a great deal has been done during the last few years. The work, however, appears to be more expensive, so I hope that it is more efficient!

I see at Cambridge it cost nearly 5 s. for each child treated.

\title{
TUBERCULOSIS.
}

Report I (page 64) states that I94,740 children examined in the ordinary routine in elghty-five areas furnished 1,986 cases of some form of tuberculosis, being I 02 per cent.

In the second Report, out of 522,000 routine exammations, the percentage is 075 .

Report 2 (page 63) states that tuberculosis in some forms was found in 1,276 children, out of 210,038 examined in counties; and in 1,009 out of 135,022 examined in towns- 0.59 and 075 per cent. approximately.

The third Report (page $7 \mathrm{I}$ ) gives a Table showing that in 88 areas there was a percentage of tuberculosis of 0.67 in 543,594 children in routine examination.

Of course this is only the percentage in the supposed healthy children on the rolls who were present at the routine examination.

\section{ADDENDUM ON SANITATION OF SCHOOL PREMISES.}

Each of the three Reports deals with the following points :-

\author{
Ventrlation \\ Lighting. \\ Heatıng arrangements. \\ Equipment (unsuitable desks, etc.) \\ Cleanliness of Schoolrooms. \\ Cloakrooms. \\ Disinfection \\ Playgrounds. \\ Type and condition of sanitary conveniences \\ and Lavatories.
}

Would it not be a valuable prece of sanitary legislation to procure a medical report upon such matters in every primary school in Ireland? 
An independent report from school medical officers in connection with the Public Health Department upon such sanitary matters would be of material assistance to the National Board of Education in its annual struggle with an unsympathetic Treasury, and the additional advantage would be gained of the publication of these reports among the members of the local bodies concerned in the public health of the district.

It is remarkable that while the Local Government Board has a staff of some seven Medical Inspectors, the Board of National Education does not possess even one!

In addition to the good resulting from these sanitary reports upon the school premises an enormous benefit has been conferred upon the whole community by having it demonstrated (I) to the local education authorities, (2) to the Board of Education, (3) to the Government, and (4) to the general public that in England the following facts have been ascertained:-

I 2.9 per cent. of school children suffer from malnutrition in county areas, and $12.3 \mathrm{~m}$ urban areas.

30 per cent. from verminous heads or bodies amongst country girls, and 49 per cent. in city girls.

Io per cent from markedly defective vision.

From 6 per cent. to Io per cent. from deafness

From 8 per cent. to Io per cent. from adenoids, or in third Report 6.2 per cent in counties, and 57 per cent. in cities

From 52 per cent. to 99 per cent from dental affections. Between the ages of $7 \frac{1}{2}$ and $8 \frac{1}{2}, 70$ per cent. require treatment.

From tuberculosis, about o \% per cent. among routine examinations.

This is very important, but what is perhaps even more important is that not alone is it known how many children suffer from this or that disease or defect in all England, but it is also known to the local medical officer of the school. to the school teacher, and to the parents or guardians that this particular child suffers from this particular disease or defect, and curative treatment can be advised and undertaken.

It is also known to the teacher that such and such a child is liable to infect other children with disease, and the child can be excluded from school till certified safe by the medical officer.

The object of the English Education Act is not to collect statistics, but to prevent or cure the defects and diseases found in children attending elementary schools.

Ameliorative $\bar{e}$ measures have been employed by varıous agencies-the Poor Law Medical Officers, private medical 
practitioners, hospitals and charitable institutions, and voluntary care committees, with whom the school nurse and health visitor co-operate.

Also by Cliniques specially provided by the Local Education Authorities.

Some of these agencies add nothing to the expenses of the Education Authorities, while others do.

In Ireland we have already some provision-very inadequate-for the blind, the deaf, and the feeble-minded, while the Poor Law deals with cases of destitution.

The general result of the recent Education Acts in England is that something is done, or attempted to be done, to improve the physical condition of every child known to requre attention, and the Board of Education does not permit the establishment of expensive schemes of treatment, t1ll the Local Education Authorities have failed to have the work done through existing voluntary or other agencies.

It would take too long to go into the various ameliorative measures adopted, and the results reported, and I shall say nothing of the cost of treatment. We in Ireland must first have medical inspection, and know what is to be treated before counting the cost of the treatment to be undertaken

When we have medical inspection, we can call upon the State to supplement the deficiency, if yoluntary agencies and the existing Poor Law system are not able to cope with the defects discovered.

But the cost of medical inspection per se is important. Report.

We have some figures upon this matter in the first

(1) Cost of Salaries, etc., as compared with the Number of Children in Average Attendance

This 1s taken from the first report of the Chief Med1cal Officer :-

In 32 counties (out of 62) the average, cost per child in average attendance is $4.79 \mathrm{~d}$.

In 42 county boroughs (out of 73 ) it is $5.69 \mathrm{~d}$.

In 38 urban districts (out of 54 ) it is $7.56 \mathrm{~d}$.

From these figures we may make an approximate est1mate that in Ireland the cost would work out to something about $6 \mathrm{~d}$. per child in average daily attendance.

If we take the average dally attendance in Ireland to be 500,000 , the first year's expenditure would ther amount to $£ 12,500$. 


\section{i2) Cost of Salaries, etc., considered as Decimals of a Penny Rate in the $£$.}

In Counties the average cost considered in this way is $0.15 \mathrm{~d}$.

In County Boroughs, o.igd.

In Municipal Boroughs, o 23d.

In Urban Districts, $0.28 \mathrm{~d}$.

These figures show that less than $3 /$ loths of a penny rate in the $\mathscr{E} 1$ s sufficient to defray the cost of medical inspection in England and Wales

The cost of medical inspection has not been estimated in either the second or third reports, but Sir George Newman has very kindly written to me as follows:-

"A rough general estımate has been made by a number of the local Education Authorities themselves, which would appear to indicate that as much as a quarter of a million (£250,000), (or, say, approximately, 35. per child inspected), is spent annually out of the rates by the 319 local Education Authorities in the work of medical inspection."

"Such a sum might, I think, be taken to include not only the salaries of the 995 Medical Officers engaged in the school medical service, but all the incidental administrative expenses involved."

Appendix A to the third Report of the Chief Medical Officer gives the total number of entrants and leavers examined as $I, 089,630$, the daily average attendance being 5,186,96I, but Sir George Newman has informed me that a large number of "specials" were also examined, and about IOO authorities inspected an intermediate group or groups of children berween "entrants" and "leavers," so that it is probable that the total number of children inspected is not so far removed from, even if it does not actually exceed, the figure of $1,600,000$ odd.

This figure represents approximately 3 I per cent. of the average dally attendance, so that we may assume that in Ireland, after medical inspection has been established three years, the same percentage in daily average attendance will be examined. My figures only deal with the schools under the National Board of Education.

In Ireland last year, the average daily attendance was 495,962 - so that by the time medical inspection has been three years in operation in Ireland, it would cost, at above rate, approximately, $£ 23,000$.

In Thom's Directory for this year, I find that the Valuation for Ireland for 1909 was $£ I_{5,647,773}$. This, 
at the rate of $I d$. in the $£$ would amount to $£ 65,199$ Is. Id., and, at $\frac{1}{2} \mathrm{~d}$. in the $£$, to $£ 32,599$ Ios. $6 \mathrm{~d}$. The expenditure on Poor Relief was Is. $5 \mathrm{~d}$. in the $£$, and the total expenditure for the same year is given as is. $9 \mathrm{~d}$. in the $£$. Therefore a rate of about $\frac{3}{8} \mathrm{~d}$. would be ample provision $=£ 24,449$.

Where is this money to come from? Either from the Treasury or the Rates. There are difficulties in obtaining the money from either source.

First as regard the Treasury-how can we bring effective pressure to bear on it?

It is obvious that the Board of National Education cannot do so. Every report of this Board for years past contains bitter, but courteously-expressed complaints that no attention has been paid to its proposals, no matter how admurable or necessary, when they involved increased expenditure.

The stereotyped beginning or end of the average paragraph in last year's Report, reads something like this:- "We protest again against the delay in acceding to the proposals we have been making for the last eight years!"

We may ask: Why do the Government disregard the recommendations and proposals of the Board of National Education?

To my mind one reason is obvious. There is no driving force behind the Board, as indeed experience would lead us to expect in the case of any Board of Government nominees. Even a Royal Commission which may be supposed to be backed by the Opposition as well as by the Government is frequently impotent.

We owe some consideration to our public-spirited fellow citizens who perform the thankless task of sitting on the Board of Education, but it is apparent that their position requires to be strengthened.

In this connection I should like to observe that there are three classes in the community who may be regarded as possessing some special knowledge of matters cognate to the bringing up of children, and these classes are not represented on the Board of National Education:

(I) The Medical Profession, which is the only class in the community which possesses any scientific knowledge of the laws and processes concerned in the formation and growth of the child's body. I say nothing of the child's mind.

(2) The mothers and women of the community generally, who may be supposed to have some knowledge about 
the growth of the child's mind and body not the common property of the other sex; and

(3) The School Teachers, who have to put into practice the schemes authorised by the Board of Education.

I firmly believe, and most readers of the daily Press during the last month will agree with me, that, if the first two of these classes, or, indeed, either one of them, were represented on the Board, it would have been absolutely impossible that the pernicious system of the long school hours with which our children are cursed in Ireland would ever have been sanctioned. Every doctor and every woman in the country knows the injury it does to the health of the children not alone in National, but also in Intermediate schools.

As to the women, I do not know how to formulate a scheme of representation, but there would be no difficulty in having representatives of medicine and school teachers elected by the respective professions. These members must be representatives, not government nominees.

This is a most important point. No doctor selected by the Government can voice the opinions of the medical profession as a representative elected by the profession can, and the same holds good of the profession of the National school teachers.

As to the second possible means of securing the money, viz., from the rates, there are also great difficulties.

I fancy an Act of Parliament would have to be enacted as in England, compelling the local authorities, County and District Councils, to appoint School Medical Officers in connection with the Public Health Department of their respective districts, and direct these Medical Officers to inspect the children and the schools, as in England.

For the purposes of the Act, the local authorities would have to be empowered to levy an educational rate of - in the $E$.

This is the proposal which has been advocated by Professor Lindsay, and I do not think it is as hopeless tc get the money from this source as from the Treasury. The Government at least would not object when the proposal is to tax ourselves.

If the cost were defrayed by an education rate, I believe it would be more advantageous to the country than a subsidy from the Imperial Parliament would be.

The difficulties in the way are very great, but I do not believe they are insuperable.

Already a considerable sum is expended by County and Urban Councils on education directly' or indirectly. 
In Ig09 nearly $£$ I 54,000 was expended by these bodies on Reformatory and Industrial Schools, Agriculture and Technical Instruction, and Compulsory Education.

Another $£ 23,000$, or less than one-sixth of above total, would finance Medical Inspection of Primary Schools.

One difficulty in the way is obvious to all of us. We know that Primary Education in Ireland is essentially a religious education. The vast majority of the National Schools in Ireland are under definite religious management-an ecclesiastic of one type or another being manager. Now, if the local elected bodies are to levy a rate for school purposes, they must have some vorce in the management of the schools, and that may raise a protest from the present managers of the schools. They may regard it as the thin end of the wedge of purely secular education.

I believe their fears are unfounded. I would not advocate the proposal if I thought otherwise, for evrn those very advanced persons who hold the views of one of the most distinguished of the Presidents of the Statistical Society - the late Dr. J. K. Ingram-and expect "Positivism" to replace "Theologism" at no distant date in Western Europe, must admit-as Dr. Ingram would himself-that purely secular education is quite unfitted for any community in the stage of development that we are in at present, and are likely to be in for a long time to come in Ireland.

There are very great advantages in having the cost of medical inspection provided by a local, and not an Imperial Authority. It will make the former take an interest in, and, I belıeve, a pride in its schools, which it has no inducement to take at present. The inspection will be undertaken by a Local Medical Officer, under the supervision of the principal Medical Officer of Health of the district, in full co-operation with the Public Health Department, and the local ratepayers will see the report upon the physical condition of the local school children, and the sanitary condition of the local schoolhouse-a report by a man they know, and not by an unknown offcral sent down by an unknown Board in Dublin.

It would be a great advantage to have (as in England) the medical inspection of schools and school childreri closely associated with and worked in full co-operation with the Public Health Department, the Public Health Officer of the district being the official head of the School Medical Officers in that district.

If the above suggestions were adopted the local authorities would defray the cost of the actual inspection of the schools in their respective localities, and all that 
the Treasury would have to supply would be funds for the expenses of the head office. Rent, furniture, salaries of officials (including the chief medical officer), printing of reports and circulars, and any other expenditure necessary for the proper co-ordination and organisation of the work throughout the country:

This amount would be so small that there would be every chance of its being obtained, especially when the request was accompanied by a proposal to raise the additional sum required locally.

Many important questions have not been dealt with in this communication, notably that most important one of the nature and extent of the share in school management to be entrusted to the local authorities. My excuse is that the real object of my paper is to elicit the opinions of more competent persons upon this and other matters connected with the health of school children rather than to advance any particular proposals of my own.

\section{APPENDIX.}

Circular to Local Education Authorties.

Schedule of Medical Inspection.

BOARD OF EDUCATION.

CIRCUlar 582.

WHITEHALL, LONDON, S.W., 23rd January, 1908.

EdUCATION (ADMinistration Provisions) ACT, I9O $\%$, SIR, SECTION 13.

I. The accompanying Schedule has been drawn up in response to requests which the Board of Education have received for further and more definite guidance as regards the details of the work of medical inspection than was given in the Memorandum (Circular 576) which was 1ssued by the Board on 22nd November, I907. The Board have, indeed, been pressed by many Local Education Authorities to issue a complete set of Forms for use in carrying out the work directly or incidentally involved in the performance of these new duties. An $r^{r}$ Forms which experience of the working of the Act may show to be necessary or desirable will be issued in due course, but for the present the Board think it expedient to leave considerable latitude, subject to the considerations hereinafter set out, in regard to the particular Forms or Schedules to be used in different cases or circumstances. 
2. The chief difficulties to be considered are administrative rather than educational or scientific. There is comparatively little dispute as to the end in view, or as to the means which, from the technical standpoint of medical science and practice, should be adopted for its complete attainment.

But the existing resources of Local Education Authorities are (for practical purposes, at all events) not unlimited, the feelings and prejudices of parents have to be considered, and a new element has to be introduced into school life and organisation with the least possible disturbance and inconvenience. Moreover, in this case two departments of local public administration are brought for the first time into organic connection--those of public health and of public education.

3. The Board are fully aware of these difficulties, and in preparing their Memorandum and Regulations it was necessary for them to consider what system would best reconcile the theoretical and practical considerations, and overcome the divergence between the ultimate end and the end immediately attainable, or between the methods which are scientifically desirable, and those which can be applied in existing circumstances at the initiation of the work under the Act.

4. In the accompanying Schedule the Board indicate the particulars, attention to which they regard as constituting the minimum of efficient medical inspection, and they consider that at least these particulars should be included in any other Schedule which the Local Education Authority may authorise for use in their schools. It deliberately excludes many points of anthropometric or statistical interest which are worthy of attention, and which it is hoped may receive attention in surtable districts. Nor does it progess to lay down the lines of a clinical study or of a scientifically complete medical examination. It is intended to indicate the methods which, in the Board's opinion, should be followed, and the particulars which should be attended to for the purpose of determining the fitness of the individual child for school life, to guide the Authority in adapting education to the peculiarities or abnormalities of the child, and to prepare the way for measures for the amelioration of defects in the child or its environment.

A more elaborate and complete form could readily be devised, but the Board's knowledge of the circumstances in which the work is to be done leads them to believe that greater elaboration would, in the majority of cases, defeat its own end.

5. If this Schedule is properly used, few cases of serious physical weakness or defect will escape detection. 
Where the ordinary inspection shows the need of further and more searching medical examination, a supplementary blank form should be used, in which particular defects or diseases should be fully recorded. It may facilitate inspection if the Schedule is printed on cards* $\left(8^{\prime \prime}\right.$ by $5^{\prime \prime}$ or $\mathrm{IO}^{\prime \prime}$ by $\left.6^{\prime \prime}\right)$. The Notes are included in the attached form for the convenience of the School Medical Officer, and should not be reprinted on the cards. Of course, it is not necessary that negative andings on all the points mentioned in the Notes should be recorded.

It will be noticed that a space is reserved in the Schedule for "General Observations"; this may conveniently be used to record a general summary of the condition of the child, and any information which may be available as to the home environment, or other conditions affecting its health.

It is considered that the inspection of each child should not occupy on the average more than a few minutes, and that the child need only, as a rule, have its clothes loosened or be partially undressed. Time may be saved in the actual inspection by the Medical Officer if the entries in some of the spaces are filled in by the school authorities before his visit. The four columns in the Schedule are designed for the four inspections required during school life.

With regard to items 17 to 24 of the Schedule, while it is necessary that all indications of diseased or unsound conditions should be thoroughly investigated, needless medical examination of healthy children should, for obvious reasons, be avorded.

6 . Where children are found to belong to that class of "defectives" for whose education special provision is or ought to be made under the Statutes relating to such children, such cases should be made the subject of a special report to the Local Education Authority.

7. All entries of the results of inspection in each individual case must be regarded as confidential.

I have the honour to be, Sir,

Your obedient Servant,

ROBERT L. MORANT.

To the Local Education Authority.

\section{NOTES FOR INSPECTING OFFICERS.}

Roference

Number of Note.

I. Date of birth to be stated exactly, date of month and year. 
2. "Other illnesses" should include any other serious disorder which must be taken into account as affecting, directly or indirectly, the health of the child in after-life, e.g., rheumatism, tuberculosis, congenital syphilis, smallpox, enterıc fever, meningitis, fits, mumps, \&c. The effects of these, if still traceable, should be recorded.

3. State if any case of, or deaths from, phthisis, \&c., in tamily.

4. Note backwardness.

5. Age to be stated in years and months, thus,

6. Insufficiency, need of repair, and uncleanliness should be recorded (good, average, bad).

7. Without boots, standing erect with feet together, and the weight thrown on heels and not on toes or outside of feet.

8. Without boots, otherwise ordinary indoor clothes.

Height and weight may be recorded in English measures if preferred. In annual report, however, the final average should be recorded in both English and metric measures.

9. General nutrition as distinct from muscular development or physique as such. State whether good, normal, below normal, or bad. Under-nourishment is the point to determine. Appearance of skin and hair, expression, and redness or pallor of mucous membrane are among the indications.

IO. Cleanliness may be stated generally as clean, somewhat dirty, dirty. It must be judged for head and body separately. The skin of the body should be examined for cleanliness, vermin, \&c.; and the hair for scurf, nits, vermin, or sores. At the same time ringworm and other skin diseases should be looked for.

I I General condition and cleanliness of temporary and permanent teeth, and amount of decay. Exceptional features, such as Hutchinsonian teeth, should be noted. Oral sepsis.

I2. The presence or absence of obstruction in the nasopharynx is the chief point to note. Observation should include mouth-breathing; inflammation, enlargement, or suppuration of tonsils; probable or obvious presence of adenoids, polypi; specific or other nasal discharge, catarrh, malformation (palate), \&c.

I3. Including blepharitis, conjunctivitis, diseases of cornea and lens, muscular defects, (squints, nystagmus, twitchings), \&c.

I4. To be tested by Snellen's Test Types at 20 feet distance ( $=6$ metres). Result to be recorded in the usual way, e.g., normal V. $=\frac{6}{6} \quad$ Examination of each eye 
544 Meducal Inspection of School Children. [Part 92,

(R. and L.) should, as a rule, be undertaken separately. 6

If the $\mathrm{V}$. be worse than -, or if there be signs of eye 9

strain or headache, fuller examination should be made subsequently. Omit vision testing of children under 6 years of age.

15. Including suppuration, obstruction, \&c.

I6. If hearing be abnormal or such as interferes with class work, subsequent examination of each ear should be undertaken separately. Apply tests only in general way in case of children under 6 years of age.

17. Including defection of articulation, lisping, stammering, \&c. \&c.

I8 Including attention, response, signs of overstrain,

The general intelligence may be recorded under the following heads:-(a) Bright, fair, dull, backward; (b) mentally defective; $(c)$ imbecile. Omit testing mental capacity of children under 6 years of age.

Ig. Under the following headings should be inserted particulars of diseased conditions actually present or signs of incipient disease. The extent of this part of the inspection will largely depend upon the findings under previous headings.

20. Include heart sounds, position of apex beat anæmia, \&c., in case of anything abnormal or requiring modification of school conditions or exercises. toms.

2I. Including physical and clinical signs and symp-

22. Including chorea, epilepsy, paralyses and nervous strains and disorders.

23. Glandular, osseous, pulmonary, or other forms. dren.

24. State particular forms, especially in younger chil-

25. Including defects or deformities of head, trunk, limbs. Spinal curvature, bone disease, deformed chest, shortened limbs, \&c.

26. Including any present infectious, parasitical or contagious disease, or any sequelæ existing. At each inspection the occurrence of any such disease since last inspection should be noted.

27. Any weakness, defect or disease not included above (e.g., ruptures) specially unfitting child for ordinary school life or physical drill, or requiring either exemption from special branches of instruction, or particular supervision. 


\section{SCHEDULE OF MEDICAL INSPECTION.}

I. - Name

Address
Date of Bnth (1)

School

II.-Personal History .

(a) Previous Illnesses of Chld (before admission).

\begin{tabular}{|c|c|c|c|c|c|}
\hline Measles & $\begin{array}{l}\text { Whooping } \\
\text { Cough }\end{array}$ & Chlckenpox & Scan let Fever & Diphthella. & Other Illnesses (2) \\
\hline
\end{tabular}

(b) Family Medical History (If exceptıonal) (3)

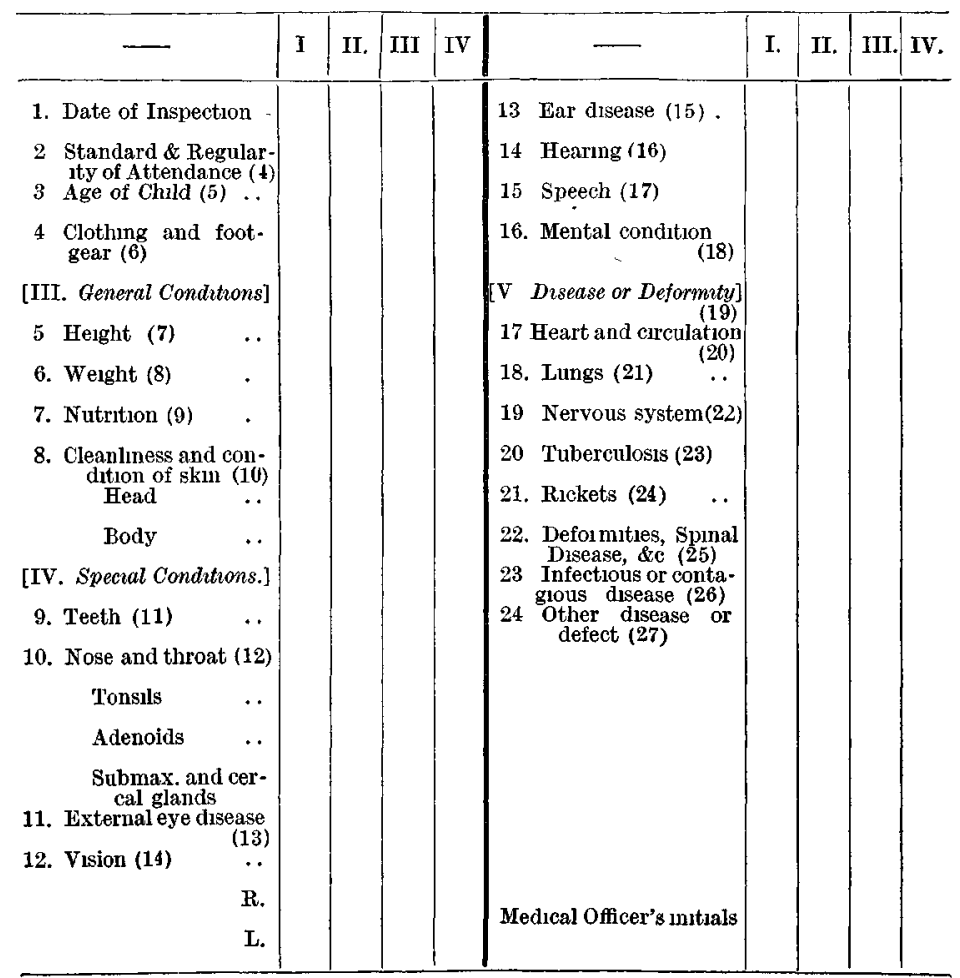

General Observatıons.

Directions to Parent or Teacher 